\title{
ASSOCIATION OF E-SELECTIN S128R POLYMORPHISM WITH HEREDITARY BREAST CARCINOMA SUSCEPTIBILITY IN TURKISH PATIENTS WITHOUT BRCA1/2 GERMLINE MUTATIONS
}

Yararbas $\mathrm{K}^{1, *}$, Atalay $\mathrm{PB}^{2}$

*Corresponding Author: Kanay Yararbas, M.D., Assistant Professor, Department of Medical Genetics, Acibadem Mehmet Ali Aydinlar University Faculty of Medicine; İçerenköy Mahallesi, Kayisdagi Caddesi, No: 32, 34742, Istanbul, Turkey. Tel: +90-216-500-4785. Fax: +90-216-500-5076. E-mail: kanay.yararbas@ acibadem.edu.tr

\begin{abstract}
Inherited genetic factors play an important role in breast cancer susceptibility. The BRCA1 and BRCA2 mutations are the most well-known genetic factors associated with increased risk of breast cancer. E-selectin is a cell surface glycoprotein and its serum levels are known to increase in various cancers. The present retrospective study aimed to evaluate whether E-selectin S128R polymorphism (NG_012124.1: g.7161A >C, NM_000450.2: c.445A >C, NP_000441.2: p.Ser149Arg), which is known to have a role in cancer risk, is associated with breast cancer susceptibility in $B R C A 1 / 2$ mutation non carriers with breast cancer. The study included 90 patients with breast cancer and 270 healthy controls. All breast cancer patients were screened for $B R C A 1 / 2$ mutations and confirmed to be $B R C A 1 / 2$ mutation non carriers before inclusion in the study. Genotyping for the E-selectin S128R polymorphism was performed using real-time polymerase chain reaction (PCR) analysis. The frequencies of the AA, AC and CC genotypes were 70.0, 25.5 and $4.5 \%$, respectively, in the patient group and $79.25,19.25$ and $1.5 \%$, respectively, in the controls. The frequencies of $\mathrm{A}$ and $\mathrm{C}$ alleles were 84.8 and $15.2 \%$ in the patient group, respectively, and 88.9 and $11.1 \%$, respectively, in the controls. No significant differences were determined in the genotype and allele frequencies of the E-selectin S128R polymorphism between the patient and control groups $(p=0.095)$. The $\mathrm{S} 128 \mathrm{R}(\mathrm{A} / \mathrm{C})$ polymorphism was not found to be associated with an increased risk of breast cancer [odds ratio $(\mathrm{OR})=0.69$;
\end{abstract}

\footnotetext{
${ }^{1}$ Department of Medical Genetics, Acibadem Mehmet Ali Aydinlar University Faculty of Medicine, Istanbul, Turkey

2 Department of Medical Biology and Genetics, Maltepe University Faculty of Medicine, Istanbul, Turkey
}

95\% confidence interval (95\% CI): $0.43-1.10 ; p=0.1248)$. There was no association between the S128R polymorphism and breast cancer susceptibility in BRCA1/2 mutation non carriers with breast cancer in the studied Turkish population. Further studies with larger sample sizes are needed to validate our findings.

Keywords: Breast carcinoma; Cancer susceptibility; E-selectin; rs5361

\section{INTRODUCTION}

Breast cancer is one of the most common invasive cancers in the female population worldwide and in Turkey [1]. Breast cancer is a multifactorial disease driven by both genetic and non genetic etiological factors. Non genetic environmental factors such as pregnancy, hormone replacement therapies, obesity and alcohol consumption are known to be closely linked to breast cancer risk [2]. The well-characterized hereditary form of breast cancer is caused by germline pathogenic variants in BRCA1/2 [3]. Early studies conducted on selected multiple-case families have estimated that approximately $80.0 \%$ of $B R C A 1 / 2 \mathrm{mu}-$ tation carriers would develop breast cancer by age $70[4,5]$. However, in a later meta-analysis study that pooled the data of studies including patients unselected for family history, it was reported that the observed risk for breast cancer development in $B R C A 1$ and $B R C A 2$ mutation carriers by age 70 was 65.0 and $45.0 \%$, respectively, which were lower than the estimated value [6,7]. Additionally, individuals of high-risk families who do not carry $B R C A 1 / 2$ mutations are also at an increased risk for developing breast cancer $[4,7]$. All these data strongly suggest that other than the well-studied $B R C A 1 / 2$ genes, additional genetic factors are also involved in a predisposition to breast cancer. However, not much is known about the genes contributing to 
breast cancer susceptibility in non carriers of the $B R C A 1 / 2$ mutations.

Selectins are adhesion molecules, which are expressed by endothelial cells, thrombocytes and leukocytes, and have three subsets, namely L-, P- and E-selectins [8]. Structurally, selectins contain an N-terminal, calciumdependent lectin domain, an epidermal growth factor-like domain, regulatory elements, a transmembrane domain, and a short cytoplasmic tail [9]. Intracellular and extracellular interactions mediated by adhesion molecules are critical for the dissemination of metastatic tumor cells. Loss of cell-cell and/or cell-matrix adhesions allows malignant tumor cells to escape from their primary micro environment and to acquire a more motile and invasive phenotype, and thereby enables them to migrate to the other sides of the body. Consistent with this, E-selectin is involved in migration and metastasis $[8,10-18]$ that are two critical steps in carcinogenesis.

E-selectin is a cell surface glycoprotein expressed on endothelial cells after activation by cytokines. Several studies have demonstrated that serum E-selectin levels are elevated in patients with a variety of cancers, including ovarian, breast and gastric cancers [14]. Numerous single nucleotide polymorphisms (SNPs) of the E-selectin gene have been identified, among which the most common variant is the $\mathrm{g} .7161 \mathrm{~A} / \mathrm{C}$ or $\mathrm{A} 561 \mathrm{C}$ missense variant (rs5361) leading to a serine to arginine substitution in exon 4 at position 128 (S128R) (NG_012124.1:g.7161A $>$ C, NM_000450.2: c.445A>C, NP_000441.2: p.Ser149Arg) [19]. The E-selectin S128R (A/C) polymorphism alters the binding specificity of the extracellular domain and thus facilitates ligand binding, which in turn improves the adhesion of lymphoid and myeloid cells to the endothelium [20-22]. In the E-selectin gene variants, the S128R polymorphism is of particular interest as it is clinically associated with increased cancer risk [23].

The present study aimed to investigate whether the S128R polymorphism of the E-selectin gene contributes to development of breast cancer in patients with breast cancer but without $B R C A 1 / 2$ mutations in the Turkish population. To the best of our knowledge, this study is the first to investigate the correlation between the S128R polymorphism and breast cancer in the absence of $B R C A 1 / 2$ mutations in the Turkish population.

\section{MATERIALS AND METHODS}

Subjects. The present study included 360 genetically unrelated females between 40-50 years of age who were referred to a regional reference laboratory between 2013 and 2016 for genetic counseling and testing. Of these females, 90 were diagnosed with breast carcinoma, clinically resembling the hereditary type according to the National Comprehensive Cancer Network (NCCN) guidelines of genetic/familial high-risk assessment for breast and ovarian cancers [24]. These patients were otherwise healthy. All patients were screened for BRCA1/2 mutations by next generation sequencing (NGS). Briefly, targeted amplification of all coding exons of BRCA1 and BRCA2 was performed using the BRCA MASTR Dx kit from Multiplicom, Agilent Technologies (Santa Clara, CA, USA), as described by the manufacturer and the amplicon pool was sequenced on the Illumina MiSeq secuencing platform. Data analysis was performed with SEQ powered by Genomize (https:// seq.genomize.com). Patients in whom normal results were obtained with no pathogenic variants were included. The control group consisted of 270 females who did not belong to an at-risk population with higher BRCA mutation carrier frequencies, such as Ashkenazi Jewish descent, who had no previous cancer diagnosis and no family history of cancer, or cardiovascular diseases hypothesized to be related with increased SELE polymorphism frequencies. The present study was approved by the Clinical Research Ethics Committee of Maltepe University, Istanbul, Turkey, and written informed consent was obtained from all participants. Histopathological data obtained from patient records revealed that all patients had invasive ductal carcinoma.

Genotyping. For genotyping analysis, DNA was extracted from ethylenediaminetetraacetic acid (EDTA)anticoagulated peripheral blood samples of all consenting subjects using the Qiagen DNA Blood Mini Kit and a QiaCube robotic device (Qiagen GmbH, Hilden, Germany) according to the manufacturer's instructions. All patients and controls were examined for the S128R (A/C) SNP of the E-selectin gene [19] by real-time (RT) polymerase chain reaction (PCR) analysis using TIB Molbiol LightSNiP Genotyping Assay (TIB Molbiol GmbH, Berlin, Germany).

The reaction master mix used in the study was commercially obtained from TIB Molbiol GmbH. The RT-PCR reactions were performed using $50 \mathrm{ng}$ genomic template DNA. The Qiagility robotic instrument (Qiagen $\mathrm{GmbH}$ ) was used to prepare the reagent mix. The RT-PCR cycling conditions used for the S128R polymorphism were as follows: $10 \mathrm{~min}$. of initial denaturation at $95{ }^{\circ} \mathrm{C}, 45$ cycling reactions of 10 seconds at $95{ }^{\circ} \mathrm{C}, 10$ seconds at $60{ }^{\circ} \mathrm{C}, 15$ seconds at $72^{\circ} \mathrm{C}$, melting curves at $95^{\circ} \mathrm{C}, 40^{\circ} \mathrm{C}, 75^{\circ} \mathrm{C}$, and cooling to $40^{\circ} \mathrm{C}$. Repeatability of the reactions was checked for internal quality control by repeating the procedure using randomly chosen samples. Melting peaks were obtained at $59^{\circ} \mathrm{C}$ for the A allele and at $64^{\circ} \mathrm{C}$ for the $\mathrm{C}$ allele. 
Statistical Analyses. Statistical analyses were performed using the Statistical Package for the Social Sciences (SPSS) Statistics for Windows version 21.0 (IBM Corporation, Armonk, NY, USA). Data were expressed as frequencies and percentages. Genotype frequencies in the patient and control groups were compared using the $\zeta^{2}$ test. Odds ratios (ORs) with $95 \%$ confidence intervals (CIs) were calculated to examine the effect of the S128R polymorphism on breast cancer susceptibility in non carriers of the BRCA1/2 mutations. A $p$ value of $<0.05$ was considered statistically significant.

\section{RESULTS}

In the present study, we genotyped 360 subjects (90 $B R C A 1 / 2$ mutation non carrier patients diagnosed with breast carcinoma and 270 controls with no previous cancer history) for the S128R polymorphism of the E-selectin gene. The genotype and allele distributions of the patients and controls are presented in Table 1.

Table 1. Distributions of genotypes and alleles in the patients and controls.

\begin{tabular}{|l|r|c|c|}
\hline $\begin{array}{l}\text { E-Selectin S128R } \\
(A / C) \text { Polymorphism }\end{array}$ & $\begin{array}{c}\text { Patients } \\
(\boldsymbol{n = 9 0 )} \\
\boldsymbol{n}(\mathbf{\%})\end{array}$ & $\begin{array}{c}\text { Controls } \\
(\boldsymbol{n}=\mathbf{2 7 0 )} \\
\boldsymbol{n}(\mathbf{\%})\end{array}$ & $\begin{array}{c}\boldsymbol{p} \\
\text { Value }\end{array}$ \\
\hline Genotypes & & & \\
\hline AA & $63(70.0)$ & $214(79.25)$ & 0.99 \\
\hline AC & $23(25.5)$ & $52(19.25)$ & 0.99 \\
\hline CC & $4(4.5)$ & $4(1.5)$ & 1 \\
\hline Alleles & & & \\
\hline A & $172(84.8)$ & $480(88.9)$ & - \\
\hline C & $31(15.2)$ & $60(11.1)$ & - \\
\hline
\end{tabular}

No significant differences were determined in the genotype and allele frequencies of the E-selectin S128R (A/C) polymorphism between the patient and control subjects (Table 1). Of the $90 \mathrm{BRCA1/2}$ mutation non carrier patients, $63(70.0 \%)$ had the AA genotype and 23 (25.5\%) had AC genotypes, and four (4.5\%) had the CC genotype. Of 270 controls, 214 (79.25\%) had the AA genotype, 52 (19.25\%) had the AC genotype, and four (1.5\%) had the $\mathrm{CC}$ genotype. The frequency of the pathogenic $\mathrm{C}$ allele was $31 / 203(15.2 \%)$ in the patient group and 60/540 (11.1\%) in the control group (Table 1); the patient and control groups did not differ in the distribution of the pathogenic C allele. The S128R (A/C) polymorphism was not found to be associated with an increased risk of breast cancer $(\mathrm{OR}=0.69 ; 95 \%$ CI: $0.43-1.10 ; p=0.1248)$.

\section{DISCUSSION}

E-selectin is involved in cancer metastasis by regulating the adhesion of circulating cancer cells to the endothelial cells of blood vessels [10]. Currently, several SNPs of the E-selectin gene have been identified. The S128R polymorphism ( $\mathrm{A}>\mathrm{C}$ variation), the most common SNP of the E-selectin gene, facilitates ligand binding, which in turn increases the adhesion of lymphoid and myeloid cells to the endothelium. The E-selectin S128R polymorphism is associated with an increased risk of several cancers including gastric [25,26], colorectal [27] and pancreatic [28] cancers. However, a very limited number of studies investigating the association of the E-selectin S128R polymorphism with breast cancer susceptibility have revealed contradictory results. Kontogianni et al. [29] reported that the E-selectin S128R genotypes (AA, AC, and CC) were not associated with any of the tumor parameters in a Caucasian population. On the other hand, Naidu et al. [30] reported that women carrying the E-selectin S128R polymorphism showed a significantly increased breast cancer risk in an Asian population. Different results from these studies may imply that the effects of the S128R polymorphism on breast cancer susceptibility may be population-dependent.

In the present study, we examined whether the S128R polymorphism is associated with susceptibility to breast carcinoma in BRCA1/2 mutation non carriers with breast cancer in the Turkish population. This study is the first to investigate the association between the E-selectin S128R polymorphism and breast cancer in the Turkish population as well as to investigate the association of the E-selectin S128R polymorphism with development of breast cancer in the absence of $B R C A 1 / 2$ mutations. For this purpose, $90 B R C A 1 / 2$ mutation non carriers with breast cancer and 270 controls with no previous cancer history, were genotyped using RT-PCR. The results of the present study demonstrated that the E-selectin S128R polymorphism was not associated with an increased risk of breast cancer in $B R C A 1 / 2$ mutation non carriers with breast cancer in the Turkish population. Further studies with larger sample sizes are required to reveal the association between the E-selectin S128R polymorphism and breast cancer risk in the absence and presence of $B R C A 1 / 2$ mutations.

\section{ACKNOWLEDGMENTS}

The authors would like to thank Mustafa Karabisici (İzmir Biomedicine and Genome Center, İzmir, Turkey), for his helpful comments on E-selectin polymorphisms; 
Günay Karataş and Serdar Kasakyan (Duzen Laboratories Group, Istanbul, Turkey), for their assistance in operating the Bio-Rad Laboratories (Hercules, CA, USA) instrument and the Qiagility robotic system (Qiagen $\mathrm{GmbH}$ ), respectively. Finally, we would like to thank Dr. Erdal Cosgun and Dr. Kimberly Cannady (Medical University of South Carolina Charleston, Charleston, SC, USA) for reviewing the statistical analysis and critical review of the manuscript. The authors declare that they all participated in the design, execution, and analyses of the study, and that they approved the final version of the manuscript.

Declaration of Interest. The authors report no conflicts of interest. The authors alone are responsible for the content and writing of this article.

\section{REFERENCES}

1. Public Health Agency of Turkey, Department of Cancer, Cancer Registry in Turkey. Available from: http:// kanser.gov.tr/daire-faaliyetleri/kanserkayitciligi/108-tırkiyede-kanser-kayitcigi.html.

2. McPherson K, Steel CM, Dixon JM. ABC of breast diseases. Breast cancer-epidemiology, risk factors, and genetics. BMJ. 2000; 321(7261): 624-628.

3. Petrucelli N, Daly MB, Pal T. BRCA1- and BRCA2Associated Hereditary Breast and Ovarian Cancer, 1998 [updated 2016]. In: Adam MP, Ardinger HH, Pagan RA, Wallace SE, Amemiya A, Bean LJH, et al., Eds. GeneReviews ${ }^{\circledR}$ [Internet]. Seattle (WA, USA): University of Washington, Seattle, WA, USA. (https:// www.ncbi.nlm. nih.gov/pubmed/20301425.)

4. Ford D, Easton DF, Stratton M, Narod S, Goldgar D, Devilee $\mathrm{P}$, et al. Genetic heterogeneity and penetrance analysis of the BRCA1 and BRCA2 genes in breast cancer families. The Breast Cancer Linkage Consortium. Am J Hum Genet. 1998; 62(3): 676-689.

5. Easton DF, Ford D, Bishop DT. Breast and ovarian cancer incidence in BRCA1-mutation carriers. Breast Cancer Linkage Consortium. Am J Hum Genet. 1995; 56(1): 265-271.

6. Antoniou A, Pharoah PD, Narod S, Risch HA, Eyfjord JE, Hopper JL, et al. Average risks of breast and ovarian cancer associated with BRCA1 or BRCA2 mutations detected in case series unselected for family history: A combined analysis of 22 studies. Am J Hum Genet. 2003; 72(5): 1117-1130.

7. Smith A, Moran A, Boyd MC, Bulman M, Shenton A, Smith L, et al. Phenocopies in BRCA1 and BRCA2 families: Evidence for modifier genes and implications for screening. J Med Genet. 2007; 44(1): 10-15.

8. Laubli H, Borsig L. Selectins promote tumor metastasis. Semin Cancer Biol. 2010; 20(3): 169-177.

9. Ley K. The role of selectins in inflammation and disease. Trends Mol Med. 2003; 9(6): 263-268.

10. Krause T, Turner GA. Are selectins involved in metastasis? Clin Exp Metastasis. 1999; 17(3): 183-192.

11. Khatib AM, Fallavollita L, Wancewicz EV, Monia BP, Brodt P. Inhibition of hepatic endothelial E-selectin expression by $\mathrm{C}$-raf antisense oligonucleotides blocks colorectal carcinoma liver metastasis. Cancer Res. 2002; 62(19): 5393-5398.

12. Laferriere J, Houle F, Taher MM, Valerie K, Huot J. Transendothelial migration of colon carcinoma cells requires expression of E-selectin by endothelial cells and activation of stress-activated protein kinase-2 (SAPK2/ p38) in the tumor cells. J Biol Chem. 2001; 276(36): 33762-33772.

13. Bal N, Kocer NE, Ertorer ME, Canpolat ET, Kayaselcuk F. Maspin, E-selectin, and P-selectin expressions in papillary thyroid carcinomas and their correlation with prognostic parameters. Pathol Res Pract. 2008; 204(10): 743-750.

14. Banks RE, Gearing AJ, Hemingway IK, Norfolk DR, Perren TJ, Selby PJ. Circulating intercellular adhesion molecule-1 (ICAM-1), E-selectin and vascular cell adhesion molecule-1 (VCAM-1) in human malignancies. Br J Cancer. 1993; 68(1): 122-124.

15. Dymicka-Piekarska V, Kemona H. Does colorectal cancer clinical advancement affect adhesion molecules (sP-selectin, sE-selectin and ICAM-1) concentration? Thromb Res. 2009; 124(1): 80-83.

16. Ke JJ, Shao QS, Ling ZQ. Expression of E-selectin, integrin $\beta 1$ and immunoglobulin superfamily member in human gastric carcinoma cells and its clinicopathologic significance. World J Gastroenterol. 2006; 12(22): 3609-3611.

17. Revelle BM, Scott D, Beck PJ. Single amino acid residues in the E- and P-selectin epidermal growth factor domains can determine carbohydrate binding specificity. J Biol Chem. 1996; 271(11): 16160-16170.

18. Alexiou D, Karayiannakis AJ, Syrigos KN, Zbar A, Sekara E, Michail P, et al. Clinical significance of serum levels of E-selectin, intercellular adhesion molecule-1, and vascular cell adhesion molecule-1 in gastric cancer patients. Am J Gastroenterol. 2003; 98(2): 478-485. 
19. Reference SNP (refSNP) Cluster Report: rs5361. Available from: http://www.ncbi.nlm.nih.gov/projects/SNP/snp_ref.cgi?rs=5361.

20. Rao RM, Clarke JL, Ortlepp S, Robinson MK, Landis RC, Haskard DO. The S128R polymorphism of Eselectin mediates neuraminidase-resistant tethering of myeloid cells under shear flow. Eur J Immunol. 2002; 32(1): 251-260.

21. Rao RM, Haskard DO, Landis RC. Enhanced recruitment of Th2 and CLA-negative lymphocytes by the S128R polymorphism of E-selectin. J Immunol. 2002; 169(10): 5860-5865.

22. Wenzel K, Hanke R, Speer A. Polymorphism in the human E-selectin gene detected by PCR-SSCP. Hum Genet. 1994; 94(4): 452-453.

23. Cheng DY, Hao YW, Zhou WL, Ma YR. E-selectin $\mathrm{S} 128 \mathrm{R}$ polymorphism is associated with cancer risk: A meta-analysis. Asian Pac J Cancer Prev. 2014; 15(7): 3247-3252.

24. NCCN Guideline. Genetic/Familial High-Risk Assessment: Breast and Ovarian Version 1, 2018. Professional version available from (subscription needed): https://www.nccn.org/professionals/physician_gls/pdf/genetics_screening.pdf.

25. Xia HZ, Du WD, Wu Q, Chen G, Zhou Y, Tang XF, et al. E-selectin rs5361 and FCGR2A rs1801274 variants were associated with increased risk of gastric cancer in a Chinese population. Mol Carcinog. 2012; 51(8): 597-607.
26. Liarmakopoulos E, Gazouli M, Aravantinos G, Theodoropoulos G, Rizos S, Vaiopoulou A, et al. E-Selectin S128R gene polymorphism in gastric cancer. Int J Biol Markers. 2013; 28(1): 38-42.

27. Hebbar M, Adenis A, Revillion F, Duhamel A, Romano O, Truant S, et al. E-selectin gene S128R polymorphism is associated with poor prognosis in patients with stage II or III colorectal cancer. Eur J Cancer. 2009; 45(10): 1871-1876.

28. Panoussopoulos GS, Theodoropoulos G, Michalopoulos NV, Gazouli M, Flessas J, Taka S, et al. Analysis of E-Selectin S128R gene polymorphism in pancreatic cancer. J Surg Oncol. 2010; 102(6): 604-607.

29. Kontogianni P, Zambirinis CP, Theodoropoulos G, Gazouli M, Michalopoulos NV, Flessas J, et al. The impact of the stromal cell-derived factor-1-3'A and E-selectin S128R polymorphisms on breast cancer. Mol Biol Rep. 2013; 40(1): 43-50.

30. Naidu R, Har YC, Taib NA. Polymorphic variant Ser128Arg of E-Selectin is associated with breast cancer risk and high grade tumors. Onkologie. 2011; 34(11): 592-597. 